Review

\title{
Reactor Design for Biogas Production-A Short Review
}

Saikat Banerjee *, Naveen Prasad, Sivamani Selvaraju

Engineering Department, University of Technology and Applied Sciences, Salalah; E-Mails: saikatban@yahoo.com; bsnaveenprasad@gmail.com; sivman.sel@gmail.com

* Correspondence: Saikat Banerjee; E-Mail: saikatban@yahoo.com

Academic Editor: Alfonso Chinnici

Journal of Energy and Power Technology

2022, volume 4, issue 1

doi:10.21926/jept.2201004
Received: September 27, 2021

Accepted: January 06, 2022

Published: January 14, 2022

\begin{abstract}
Biogas is an alternative to gaseous biofuels and is produced by the decomposition of biomass from substances such as animal waste, sewage sludge, and industrial effluents. Biogas is composed of methane, carbon dioxide, nitrogen, hydrogen, hydrogen sulfide, and oxygen. The anaerobic production of biogas can be made cheaper by designing a high throughput reactor and operating procedures. The parameters such as substrate type, particle size, temperature, $\mathrm{pH}$, carbon/nitrogen $(\mathrm{C} / \mathrm{N})$ ratio, and inoculum concentration play a major role in the design of reactors to produce biogas. Multistage systems, batch, continuous one-stage systems, and continuous two-stage systems are the types of digesters used in the industry for biogas production. A comprehensive review of reactor design for biogas production is presented in the manuscript.
\end{abstract}

\section{Keywords}

Biogas; process parameters; reactors; digesters

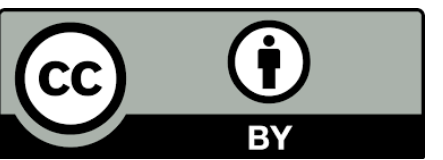

(C) 2022 by the author. This is an open access article distributed under the conditions of the Creative Commons by Attribution License, which permits unrestricted use, distribution, and reproduction in any medium or format, provided the original work is correctly cited. 


\section{Introduction}

Biogas is produced by the anaerobic digestion of organic materials such as sewage sludge, animal waste, and municipal solid waste (MSW) [1]. As a sustainable clean energy carrier, biogas is an important source of energy for heat and electricity generation as it is one of the most promising renewable energy sources in the world [2]. Biogas is produced by the anaerobic digestion (AD) of organic matter, such as manure, MSW, sewage sludge, biodegradable wastes, and agricultural slurry, under anaerobic conditions with the help of microorganisms [3].

Commercial biogas production has increased since it can be used as a fuel or source of energy, while also contributing to lower GHG concentrations when collected in a closed process and not released into the atmosphere. The biogas produced contains $50-70 \% \mathrm{CH}_{4}$ and $30-50 \% \mathrm{CO}_{2}$, with minor components such as hydrogen sulfide $\left(\mathrm{H}_{2} \mathrm{~S}\right)$, nitrogen $\left(\mathrm{N}_{2}\right)$, oxygen $\left(\mathrm{O}_{2}\right)$, siloxanes, volatile organic compounds (VOCs), carbon monoxide (CO), and ammonia $\left(\mathrm{NH}_{3}\right)$. Biogas usage is expected to double in the next few years, from $14.5 \mathrm{GW}$ in 2012 to $29.5 \mathrm{GW}$ in 2022, according to estimates [4]. The components present in biogas comprise methane (55-75\%), carbon dioxide (25-45\%), nitrogen (0-5\%), hydrogen (0-1\%), hydrogen sulfide (0-1\%), and oxygen (0-2\%) [5]. Sewage sludge mainly contains proteins, sugars, detergents, phenols, and lipids [6].

During biogas production, biopolymers are converted to biogas under anaerobic conditions [7]. Anaerobic digestion involves hydrolysis, acidogenesis, acetogenesis, and methanogenesis [8]. Hydrolysis involves the breakdown of biopolymers into their monomers in the presence of water [9]. Acidogenesis involves the formation of volatile acids from monomers [10]. Acetogenesis produces acetates and acetic acid from various volatile acids [11]. Finally, acetates and acetic acid are converted to methane and carbon dioxide during methanogenesis [12]. Anaerobic digestion occurs in the presence of co-cultures containing hydrolytic, acidogenic, acetogenic, and methanogenic organisms [13].

The development of sludge bed anaerobic digester, granular sludge-based bioreactors like the up-flow anaerobic sludge blanket, and the anaerobic hybrid reactor have considerably enhanced the anaerobic digestion technology in the last two decades. Biogas plants are suitable for treating municipal and agro-industrial organic leftovers cost-effectively, as well as, producing territorially diffused electric and thermal power [14, 15].

Biogas can be used as a cooking fuel, lighting fuel, and for pumping water and running IC engines [16]. The challenges in biogas production are high retention time, lower biogas yield, and design constraints due to environmental conditions [17]. Hence, in this study, a comprehensive review of the processes and parameters affecting biogas production and reactor design for biogas production is presented [18].

The presence of siloxanes and other components such as halogenated compounds, VOCs, and hydrogen sulfide is a major issue in waste management and sewage treatment. These contaminants in biogas not only cause overheating of sensitive motor parts but also impair the function of pistons and spark plugs in Combined Heat and Power units (CHP); they also damage the upgrade system and gas grid pipelines $[19,20]$.

Siloxanes are a class of silica-organic chemicals that contain silicon, oxygen, and methyl groups. They are mostly used in industries (as fuel additives, automobile polish, cleaners, and waxes), consumer products (barrier cream and cosmetic products), elastomers (silicone components and tubing), and medicine (implants in cosmetic surgery and coating pacemakers, among others). The 
ubiquitous usage of siloxanes, their wide range of applications, and their high volatility have prompted concerns regarding them in various areas of environmental science. Volatile matters (VMs) are found in the garbage and disposed of in landfills [21].

\section{Factors Affecting Biogas Production}

Biogas is produced through four complex biochemical processes (hydrolysis, acidogenesis, acetogenesis, and methanogenesis) that are influenced by several parameters, including substrate type, particle size, temperature range, $\mathrm{pH}$, carbon/nitrogen $(\mathrm{C} / \mathrm{N})$ ratio, and inoculum concentration. Biogas production by anaerobic digestion is influenced by several factors. Some of the most important elements are discussed below in detail $[22,23]$.

\subsection{Hydrogen-ion $(\mathrm{pH})$ concentration}

Anaerobic digestion is influenced by the concentration of hydrogen ions $(\mathrm{pH})$ present in the digesting material. Because excess acidity prevents digestion, the hydrogen-ion concentration of the culture medium immediately influences microbial growth. Methanogens thrive in neutral to slightly alkaline conditions and die in acidic environments. The optimum $\mathrm{pH}$ of the system is in the range of $7-8.5$, with values approaching 7 for optimal activity when the aerobic digestion process is stable [24].

\subsection{Temperature}

The temperature of MSW affects the digestion process since the anaerobes that cause trash decomposition are temperature sensitive. The operating temperatures of the reactor strongly affect the optimal performance of an aerobic digestion system. Psychrophilic: around $10-20{ }^{\circ} \mathrm{C}$ (or less than $30{ }^{\circ} \mathrm{C}$ ), mesophilic: about $30-40^{\circ} \mathrm{C}$, and thermophilic: about $50-55^{\circ} \mathrm{C}$ (or may reach $60^{\circ} \mathrm{C}$ ) are the three general temperature ranges that each favor a unique species of microorganism [25]. Anaerobic bacteria are the most active microorganisms in the mesophilic and thermophilic ranges, according to previous studies $[8,15,25]$. Extreme temperatures, either very high or very low, destroy the anaerobes, effectively stopping the AD process. Temperature affects the rate of decomposition and gas production, and generally, the processes accelerate at higher temperatures; the ideal temperature is $35^{\circ} \mathrm{C}$. Process reaction, mixing (impellers), and heat exchangers are some parameters that contribute to heat creation or transfer in a digester by hot water or steam to the feedstock composition and nutrients [26]. Different kinds of digesters exist for the anaerobic treatment of organic wastes [15].

Biowaste, agricultural waste, human waste, municipal sewerage, and animal manure, among other biomass feedstocks, could be used for anaerobic digestion. The nature of the feedstock used determines the quality and amount of biogas produced [27]. Besides producing biogas, biomass produces essential nutrients and carbon which aid in the long-term survival of the bacteria. The kind of biomass selected is based on operational considerations, such as the nature of the waste to be processed, for example, solid waste [28]. According to the Oregon Department of Energy, a plugflow digester is appropriate for ruminant animal dung with solid concentrations of $-11-13 \%$. A complete-mix digester is appropriate for manure that is $-2-10 \%$ solids [29]. A covered lagoon digester is used for liquid manure with less than $2 \%$ solids. The amount and kind of solids in the 
studied waste were such that the wastes could flow on their own or form slurries with water before eventually flowing, allowing them to be used continuously [26].

\subsection{Carbon/Nitrogen (C/N) Ratio}

The efficiency of anaerobic digestion depends on carbon and nitrogen concentrations. The optimal $\mathrm{C} / \mathrm{N}$ ratio for anaerobic digestion is between 20:1 and 30:1. The carbon-to-nitrogen ratio in the raw material should be around 30:1 for optimal performance. Nitrogen is used by methanogenic bacteria to meet their protein requirements. Carbon serves as a source of energy for microbes, while nitrogen promotes microbial development. When nitrogen is scarce, microbial populations are small, and decomposition of the remaining carbon takes longer. Thus, when the $\mathrm{C} / \mathrm{N}$ ratio is higher than the ideal range, nitrogen is quickly utilized by the bacteria, preventing the extra carbon in the feedstock from reacting and lowering the biogas yield [30]. When the ratios are lower than the specified range, the excess nitrogen is used to synthesize ammonia (a strong base), which raises the working $\mathrm{pH}$ over 8.5; thus, inhibiting bacteria and eventually lowering gas generation rates. The bacteria in the digestion process utilize the carbon present 30-35 times faster than they convert nitrogen, according to some studies [23, 24]. Because of the high nitrogen content in animal manure, its usage in anaerobic digestion for biogas generation is limited due to the $\mathrm{C} / \mathrm{N}$ ratio. To solve this problem, a nitrogen-free raw material or a carbohydrate-rich source is used to increase the carbon content of animal manure before the AD process [31].

\subsection{Substrate Particle Size}

Biomass should be pretreated to reduce particle size, then co-digestion should be performed to boost biogas generation. Anaerobic digestion requires a substrate made up of digestible particle sizes. Smaller particles increase the surface area available to the methanogens for microbial action, increasing the feedstock's biodegradability, and hence, the rate of biogas generation, while larger particles can clog the digester [32].

\section{Reactors for Biogas Production}

There are many different types of reactors used for biogas production, each of which is used for a specific purpose. Some of these are used to remove contaminants from wastewater, while others are used for biogas production.

A plug flow digester works similar to a complete mix digester in that the manure flowing into it displaces digestion volume, and an equivalent quantity of material flows out. The manure from a plug flow digester, however, is thick enough to prevent particles from settling at the bottom. The biotrickling filter and biofilm reactor is a three-phase system widely used in wastewater treatment plants for the treatment and reduction of BOD, COD, pathogens, and odor. The sewage is filtered and divided in an anaerobic contact reactor; thus, leaving the effluent and sludge separate. Mesophilic bacteria process the sludge anaerobically, releasing methane as a byproduct. The biogas can be combusted later to generate heat or electricity. The simplest reactor vessel used in chemical or industrial operations is a batch reactor. A typical batch reactor consists of a tank in which chemical reactions occur. An agitator and an internal heating or cooling system are also included in these tanks. An anaerobic baffled reactor (ABR) is a type of septic tank that has a series of baffles 
through which grey, black, or industrial wastewater is pushed and made to flow from the entrance to the output. Treatment is improved due to increased contact time with the active biomass (sludge). In a study, a hybrid biological reactor (HBR) was constructed, which could add carriers to the aeration tanks to introduce a new phase of attached biomass into a standard suspended-growth system (active sludge process) [33].

\section{Design of Reactors for Biogas Production}

The pricing, building materials, and design complexity of digesters vary globally. To build any anaerobic digester, we must first address the three main requirements: producing a large volume of high-quality biogas; being able to manage a high organic loading rate continuously; having a short hydraulic retention period to reduce reactor volume. Multistage systems, batch, continuous onestage systems, and continuous two-stage systems are the most common types of digesters used in the industry [33].

Plug-flow systems, anaerobic sequencing batch reactors (ASBR), tubular reactors, baffled digesters (ABR), up-flow anaerobic sludge blanket (UASB) reactors, and anaerobic filters are among the other types of reactors available. Typically, the main feedstock qualities, specifically total solid, are used to determine which digester type is appropriate. Continuous stirred tank reactors (CSTRs) are used to treat feedstocks with a large content of total solids and slurry, while soluble organic wastes are mostly digested in up-flow anaerobic sludge blanket (UASB) reactors, anaerobic filters, and fluidized bed reactors. Co-digestion is the most commonly used technique in single-step wet procedures (e.g., CSTR) [34].

Continuous systems are fed constantly, and the digestate residue is discharged at the same rate, resulting in a steady-state and a constant gas production rate. They are limited to substrates that can be pumped for continuous feeding. Alternatively, a semi-continuous method is used multiple times a day with a specific amount of feed. Continuous systems have several advantages, including ease of design, operation, and low capital costs, but they also have drawbacks, such as quick acidification and high volatile fatty acid (VFA) production [14].

\subsection{Anaerobic Plug-flow Reactor (APFR)}

APFRs (anaerobic plug-flow reactors) are long rectangular channels with the flow entering from one end and exiting from the other; mixing occurs only infrequently. The tanks, or channels, are generally aboveground. Some procedures are both thermophilic and mesophilic. APFRs are highrate digesters that are commercially used to treat different kinds of organic wastes, such as animal manure slurries, distillery effluent, and the organic part of municipal solid waste. Plug-flow reactors are more efficient in converting the substrate to biogas and are more stable while operating than single-stage CSTRs [35].

Continuous stirred-tank reactors (CSTRs, which use biogas recirculation for mixing or mechanical agitation or effluent) and plug-flow reactors are the two types of reactors that are most frequently used (PFR, where the reactor content is shoved along a horizontal reactor). PFRs are typically used for dry digestion to treat substrates with high solid content, while CSTRs are used in wet digestion systems. The total solid content (TS) of the material to be digested determines whether wet or dry digestion needs to be performed. In industrialized countries, CSTR and PFR systems, as well as, 
covered lagoons and other types of anaerobic reactors are commonly used to recover biogas from manure [36].

\subsection{Biofilm Reactor}

Microbial consortia connected to a support material are called biofilms. Generally, the support surface is inert and can be fastened or suspended. Biogas can be produced by anaerobic microbial biofilm digesting organic matter. Biofilm reactors can retain high organic loads and withstand changes in hydraulic or organic loads owing to a large mass of immobilized biofilm and mass-transfer upgrading motion of the liquid around the film. Compared to other classic anaerobic treatment systems, start-up times are low after the formation of the biofilm (Figure 1). The improvement and intensity of attachment and the mechanical stability of biofilms are influenced by the composition of the support material [32].

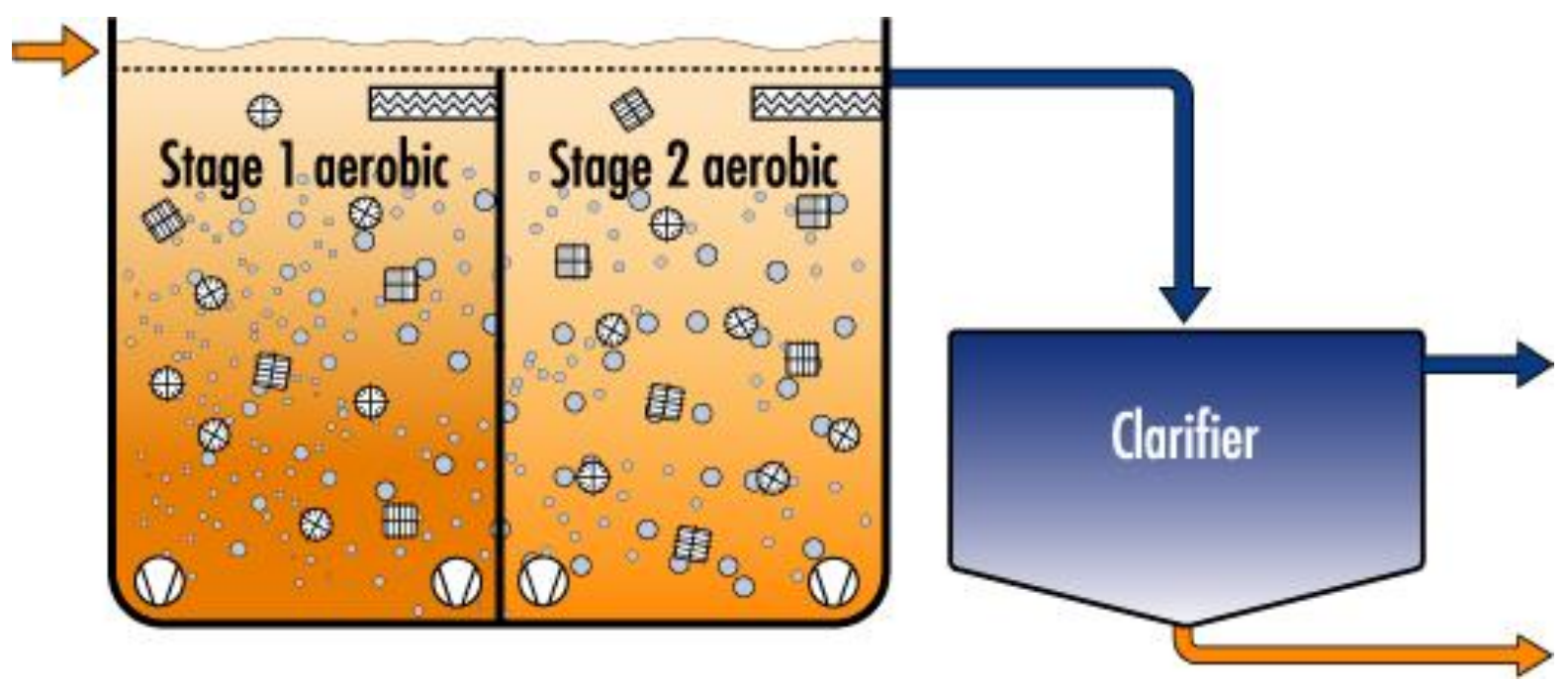

Figure 1 Biofilm reactor.

\subsection{Continuous Flow Stirred-tank Reactor (CSTR)}

CSTRs (continuous flow stirred-tank reactors) are high-rate digesters that are perhaps the most used reactors for biogas production. They are appealing because their design is simpler than that of other forms of methane digesters [37]. CSTRs are most used to handle slurries with a total solids content of $5-10 \%$. CSTRs are used to remediate slurries of animal manure and organic industrial wastes. The drawback of CSTRs is that they have extended retention durations and may use more energy than other types of reactors (Figure 2). The performance of CSTRs can be improved by recycling microbial solids or increasing active biomass retention [24]. 


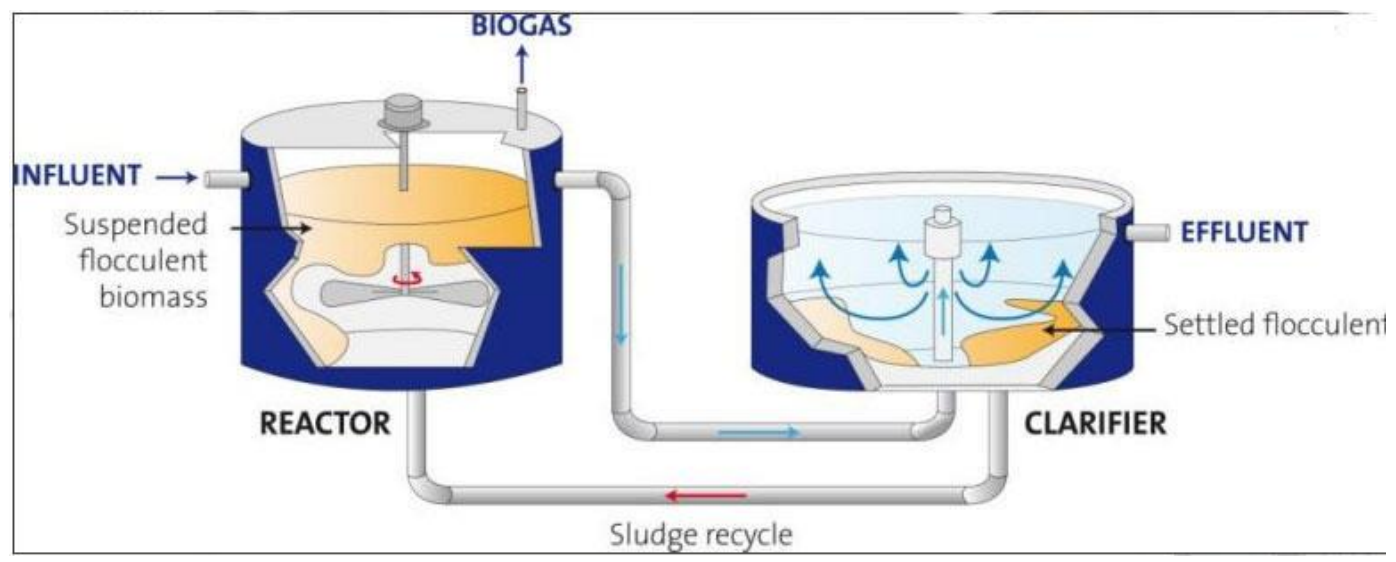

Figure 2 Continuous flow stirred-tank reactor.

\subsection{Anaerobic Contact Reactor (ACR)}

ACR (anaerobic contact reactor) is a completely mixed mechanically stirred tank with sludge recycling. The effluent from the tank is pumped into a solid-liquid separator (such as a gravity sedimentation tank, a sludge flotation device, or a lamella clarifier), where the solids are recovered and reintroduced to the anaerobic digester. Due to the high concentration of active microbial biomass, ACRs are effective in treating high-strength waste with a high concentration of digestible solids. The duration of hydraulic retention is short, and changes in organic loading are easily handled. ACRs are less susceptible to sourness and other inhibitors (Figure 3). Stirred digesters with membrane-based cell retention are highly effective in biogas production [38].

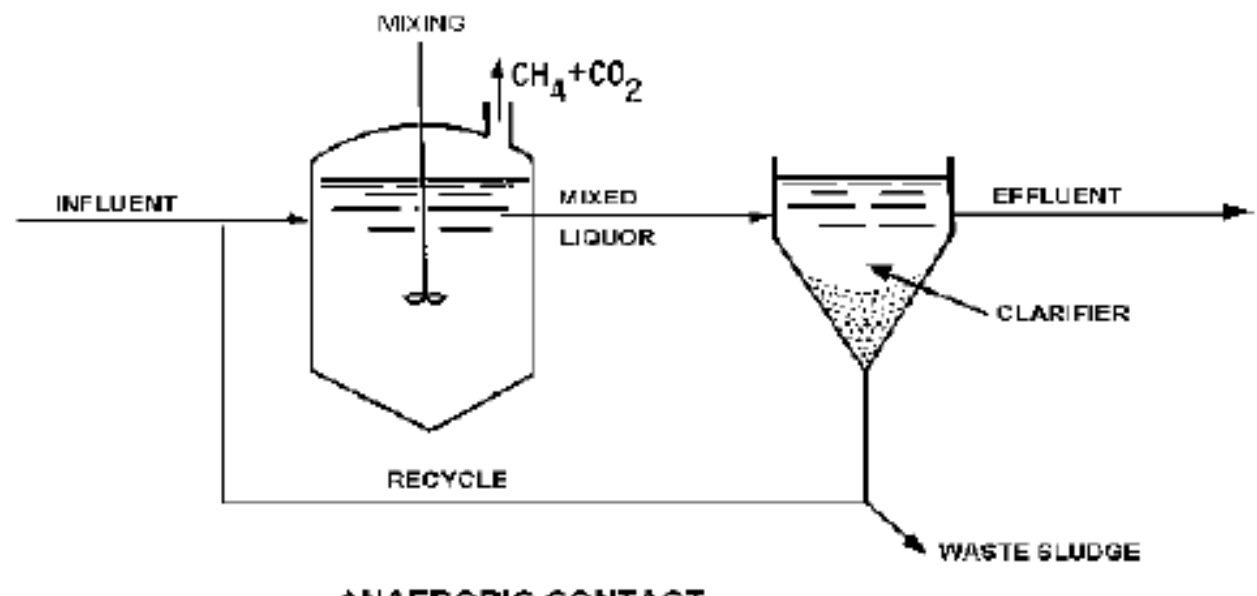

ANAEROBIC CONTACT

Figure 3 Anaerobic contact reactor (ACR).

\subsection{Batch Reactor}

Batch reactors are the simplest to operate because they are fed with feedstock and left for a longer duration before being emptied. Mixing, stirring, or pumping is not required, and they have a low capital cost. However, they show channeling and clogging, and they also have a higher volume and lower biogas yield (Figure 4). Methane production is typically highest at the start of the process and diminishes as the substrate is consumed toward the end [22]. 


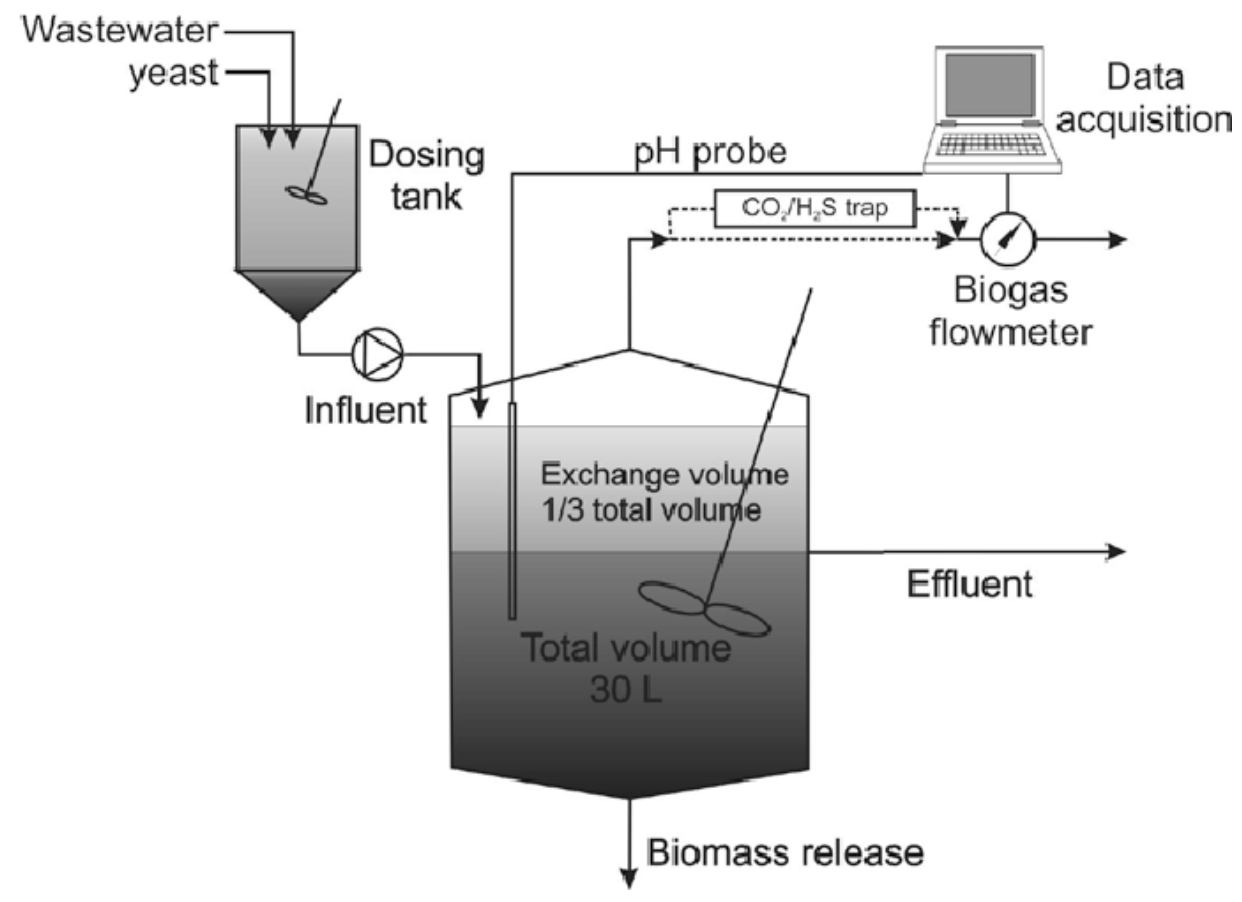

Figure 4 Batch reactor.

\subsection{Anaerobic Baffled Reactor (ABR)}

Up-flow Anaerobic Sludge-Bed Reactor (UASBR) is a variant of the Anaerobic Baffled Reactor (ABR). The organic fraction of the municipal solid waste (OFMSW) is fed into an anaerobic baffled reactor ( $A B R)$, which then decomposes the materials and generates biogas through microbial activity. This type of reactor can treat wastes with high solid content, making it a feasible option in some developing countries. Treatment improves as contact time with the sludge (active biomass) increases (Figure 5). ABRs can be used to treat a wide range of wastewater. However, the remaining effluents and sludge require additional treatment before being discharged or to be reused correctly [32].

\section{Anaerobic Baffled Reactors (ABR)}

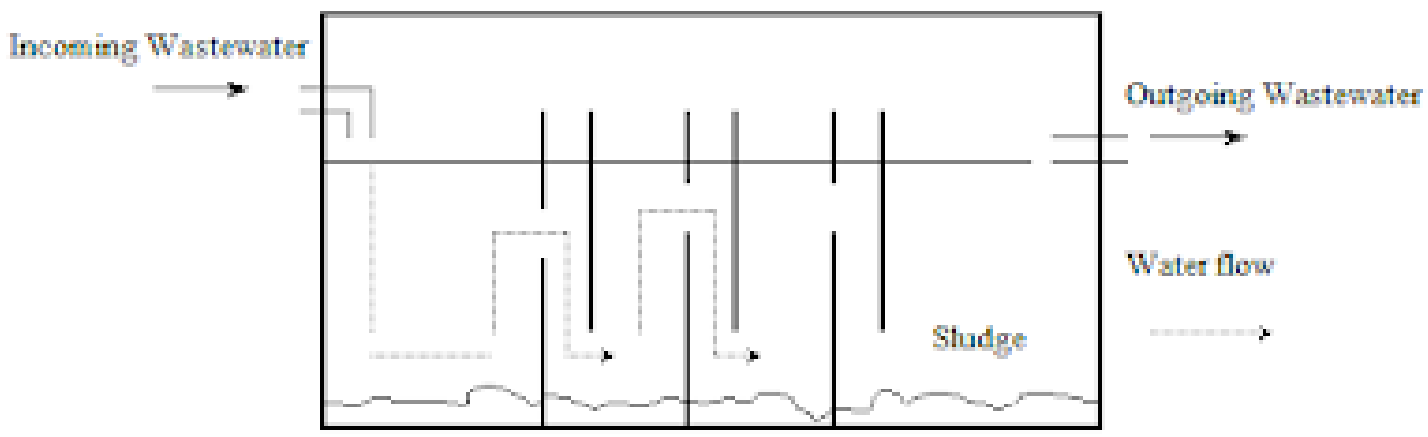

Figure 5 Anaerobic baffled reactor. 


\subsection{Hybrid Bioreactor}

The hybrid bioreactor is a new type of reactor that combines the advantages of both suspended solids and biofilm reactors. They combine the advantages of the UASB concept with those of anaerobic filters and are considered to be better than other reactor systems for the treatment of soluble or partially soluble wastewater (Figure 6). This category includes hybrid reactors (combinations of the fundamental types) and anaerobic baffled reactors (ABRs) [39].

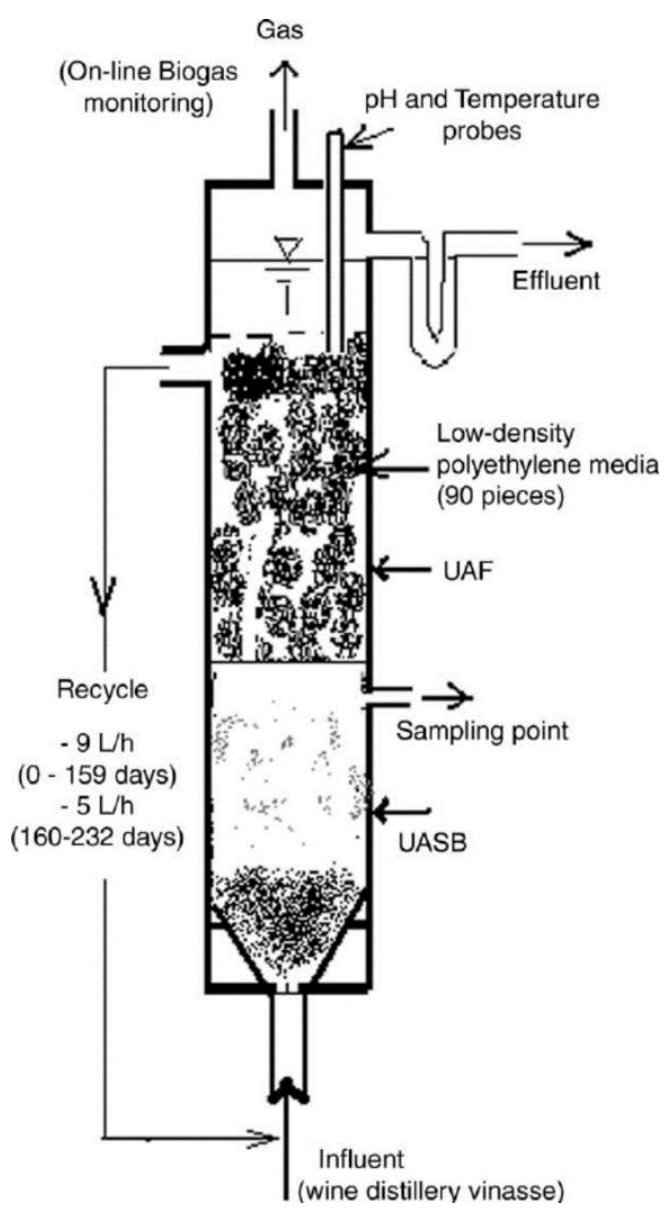

Figure 6 Hybrid reactor.

Various kinds of aerobic digesters with different systems of operation have been developed for use in a variety of applications. Shortening the start-up time, reducing operating instabilities, reducing washout of active biomass, and improving the acceptance of the unavoidable fluctuations in feed composition are all common goals. Other costs such as operation, maintenance, and installation have a significant impact on the economics of biogas generation [4].

Because of their simplicity, single-stage digesters are most commonly used; however, two-stage digesters are better overall. No specific digester type can be regarded as being suitable for universal use. The following factors must be considered when deciding according to each scenario: the prospects for digestate and effluent disposal; the nature and strength of the waste stream; the availability and skill level of the local workforce; local climatic conditions, infrastructural support, and energy cost; the cost of construction and operation. Using AD to generate biogas is a useful way to recover energy from organic wastes while also lowering the environmental impact of the waste [36]. 
CSTR is the most commonly used procedure in single-stage systems, where the reactor favors both methanogenic and acidogenic bacteria. These systems offer lower capital and operational costs and are easy to use, which made them appealing for a wide range of applications in the last few decades. Furthermore, the conversion of organic matter to biogas requires several biochemical events that may not always occur under the same ideal environmental conditions. Single-stage digesters have a basic design and are less likely to fail due to technical issues. However, they have longer retention times and produce froth and scum, which might lead to failure. Two-stage and multistage systems have been developed to provide optimal conditions for the various groups of microorganisms involved in degradation, resulting in higher reaction rates, and thus, a higher biogas output [19].

For AD, two-stage reactors perform four processes (hydrolysis, acidification, acetogenesis, and methanogenesis). The first stage can be performed at a lower $\mathrm{pH}$, which favors the growth of acidogenic and hydrolytic microbes, while the second stage can be performed at a higher $\mathrm{pH}$, which favors the growth of methane-forming microorganisms. The pace of microbial growth is usually the limiting factor in the second step, because longer generation durations for methane-producing archaea, and thus, longer biomass retention times, are required in this stage, which enhances the biogas yield. Because they do not suffer from the disruptions produced by the accumulation of ammonia and $\mathrm{pH}$ variations, these digesters usually have a more consistent performance than single-stage digesters [40]. Multistage reactors, which may enable optimization and process control at each conversion point, can provide the best phase extraction option, resulting in increased methane generation. Due to recirculation, two-stage reactors increase biomass digestion, provide a consistent feeding rate to the methanogenic step, and are more robust and less prone to failure. However, it is sophisticated and is costly to build and maintain; solid particles from the feedstock must be removed before processing [24].

\section{Challenges and Future Prospects}

Anaerobic digestion may be conducted by a single or two-stage procedure. Although single-stage processing is inefficient, it is the most frequently used method due to its simplicity. Traditional single-stage digesters are often larger, requiring more energy to mix and heat than two-stage digesters; two-stage digestion is more efficient than single-stage digestion [41].

\section{Conclusion}

A comprehensive review of reactor design for biogas production was presented with more emphasis on reactor design. The parameters, including substrate type, particle size, temperature range, $\mathrm{pH}$, carbon/nitrogen $(\mathrm{C} / \mathrm{N})$ ratio, and inoculum concentration, play a major role in biogas production.

The reactor design and the types of reactors used to produce biogas play a vital role in the yield of biogas. The selection of the reactor mainly depends on the production of a large volume of highquality biogas, management of a high organic loading rate, and a short hydraulic retention period to reduce reactor volume. The pricing, building materials, and design complexity of digesters vary globally. To build any anaerobic digester, we must first address three main requirements: producing a large volume of high-quality biogas, being able to manage a high organic loading rate continuously, and having a short hydraulic retention period to reduce reactor volume. Multistage systems, batch, 
continuous one-stage systems, and continuous two-stage systems are the most common types of digesters used in the industry. Plug-flow systems, anaerobic sequencing batch reactors (ASBR), upflow anaerobic sludge blanket (UASB) reactor, and anaerobic filters, tubular reactors, and baffled digesters are examples of other layouts. The qualities of the main feedstock used, specifically total solid, are used to determine which digester type is appropriate. CSTRs are used to treat feedstocks with a large content of total solids and slurry, while soluble organic wastes are mostly digested in up-flow anaerobic sludge blanket (UASB) reactors, anaerobic filters, and fluidized bed reactors.

Co-digestion is most commonly used in single-step wet procedures (e.g., CSTR). Continuous systems are fed constantly, and the digestate residue is discharged at the same rate, resulting in a steady state and the production of gas at a constant rate. Regardless, this type of operation is limited to substrates that can be pumped for continuous feeding. Alternatively, a semi-continuous method is used multiple times a day with a specific amount of feed. Continuous systems have several advantages, including ease of design, operation, and low capital costs, but they also have drawbacks, such as quick acidification and higher volatile fatty acid (VFA) production.

Sustainable development needs methods and tools to measure and compare the influence of goods and services of the environment on society.

\section{Author Contributions}

Saikat Banerjee: Conceptualization, Investigation, Methodology, Project administration, Supervision, Writing - original draft, Writing - review \& editing. Naveen Prasad: Investigation, Writing - review \& editing. Sivamani Selvaraju: Conceptualization, Investigation, Writing - original draft, Writing - review \& editing.

\section{Competing Interests}

The authors have declared that no competing interests exist.

\section{References}

1. Valijanian E, Tabatabaei M, Aghbashlo M, Sulaiman A, Chisti Y. Biogas production systems. In: Biogas. Cham: Springer; 2018. pp.95-116.

2. Tufaner F, Demirci Y. Prediction of biogas production rate from anaerobic hybrid reactor by artificial neural network and nonlinear regressions models. Clean Technol Environ Policy. 2020; 22: 713-724.

3. Dong L, Cao G, Tian Y, Wu J, Zhou C, Liu B, et al. Improvement of biogas production in plug flow reactor using biogas slurry pretreated cornstalk. Bioresour Technol Rep. 2020; 9: 100378.

4. Piechota G. Multi-step biogas quality improving by adsorptive packed column system as application to biomethane upgrading. J Environ Chem Eng. 2021; 9: 105944.

5. Sivamani S, Prasad BS, Al-Sharji ZA, Al-Rawas KA, Al-Blowshi AS, Al-Yafii AS, et al. Stoichiometric analysis of biogas production from industrial residues. In: Biofuel production technologies: Critical analysis for sustainability. Singapore: Springer; 2020. pp.141-153.

6. Sivamani S, Chandrasekaran AP, Balajii M, Shanmugaprakash M, Hosseini-Bandegharaei A, Baskar R. Evaluation of the potential of cassava-based residues for biofuels production. Rev Environ Sci Biotechnol. 2018; 17: 553-570. 
7. Demirbas A, Taylan O, Kaya D. Biogas production from municipal sewage sludge (MSS). Energ Source Part A. 2016; 38: 3027-3033.

8. Sivamani S, Binnal P, Cuento A, Al-Shahri A, Al-Mahri M, Rafeet $M$, et al. A comprehensive review of experimental studies on aerobic digestion of wastewater sludge. In: Removal of toxic pollutants through microbiological and tertiary treatment. Amsterdam: Elsevier; 2020. pp.211231.

9. Sarker S, Lamb JJ, Hjelme DR, Lien KM. A review of the role of critical parameters in the design and operation of biogas production plants. Appl Sci. 2019; 9: 1915.

10. Jafari-Sejahrood A, Najafi B, Faizollahzadeh Ardabili S, Shamshirband S, Mosavi A, Chau KW. Limiting factors for biogas production from cow manure: Energo-environmental approach. Eng Appl Comput Fluid Mech. 2019; 13: 954-966.

11. Fardad K, Najafi B, Ardabili SF, Mosavi A, Shamshirband S, Rabczuk T. Biodegradation of medicinal plants waste in an anaerobic digestion reactor for biogas production. Comput Mater Contin. 2018; 55: 318-392.

12. Ebrahimi A, Hashemi H, Eslami H, Fallahzadeh RA, Khosravi R, Askari R, et al. Kinetics of biogas production and chemical oxygen demand removal from compost leachate in an anaerobic migrating blanket reactor. J Environ Manage. 2018; 206: 707-714.

13. Loganath R, Mazumder D. Performance study on organic carbon, total nitrogen, suspended solids removal and biogas production in hybrid UASB reactor treating real slaughterhouse wastewater. J Environ Chem Eng. 2018; 6: 3474-3484.

14. Piechota G. Biogas/biomethane quality and requirements for combined heat and power (CHP) units/gas grids with a special focus on siloxanes-a short review. Sustain Chem Eng. 2022; 3: 110.

15. Ghosh P, Kumar M, Kapoor R, Kumar SS, Singh L, Vijay V, et al. Enhanced biogas production from municipal solid waste via co-digestion with sewage sludge and metabolic pathway analysis. Bioresour Technol. 2020; 296: 122275.

16. Khan EU, Martin AR. Optimization of hybrid renewable energy polygeneration system with membrane distillation for rural households in Bangladesh. Energy. 2015; 93: 1116-1127.

17. Mukumba P, Makaka G, Mamphweli S. Biogas technology in South Africa, problems, challenges and solutions. Int J Sustain Energy Environ Res. 2016; 5: 58-69.

18. Franks L, Euston-Brown M, Ferry A, Giljova S. Municipal wastewater treatment works-biogas to energy. GIZ-SALGA municipal renewable energy case study series [Internet]. SALGA: Johannesburg; 2013. Available from: https://cityenergy.org.za/uploads/resource 360.pdf.

19. Amaral AF, Previtali D, Bassani A, Italiano C, Palella A, Pino L, et al. Biogas beyond CHP: The HPC (heat, power \& chemicals) process. Energy. 2020; 203: 117820.

20. Piechota G, Igliński B, Buczkowski R. Development of measurement techniques for determination main and hazardous components in biogas utilised for energy purposes. Energy Convers Manag. 2013; 68: 219-226.

21. Piechota G. Removal of siloxanes from biogas upgraded to biomethane by cryogenic temperature condensation system. J Clean Prod. 2021; 308: 127404.

22. Lisowyj M, Wright MM. A review of biogas and an assessment of its economic impact and future role as a renewable energy source. Rev Chem Eng. 2020; 36: 401-421.

23. Dioha IJ, Ikeme CH, Nafi'u T, Soba NI, Yusuf MB. Effect of carbon to nitrogen ratio on biogas production. Int Res J Nat Sci. 2013; 1: 1-10. 
24. Ganguly A, Banerjee S, Biswas GK. Studies on biomethanation of kitchen wastes. Indian J Environ Prot. 2006; 26: 219.

25. Guo J, Peng Y, Ni BJ, Han X, Fan L, Yuan Z, et al. The microbiology of anaerobic digesters. Environ Technol. 2015; 14: 1-11.

26. Ngan NV, Chan FM, Nam TS, Van Thao H, Maguyon-Detras MC, Hung DV, et al. Anaerobic digestion of rice straw for biogas production. In: Sustainable rice straw management. Cham: Springer; 2020. pp.65-92.

27. Ruan D, Zhou Z, Pang H, Yao J, Chen G, Qiu Z. Enhancing methane production of anaerobic sludge digestion by microaeration: Enzyme activity stimulation, semi-continuous reactor validation and microbial community analysis. Bioresour Technol. 2019; 289: 121643.

28. Lebiocka M, Montusiewicz A, Cydzik-Kwiatkowska A. Effect of bioaugmentation on biogas yields and kinetics in anaerobic digestion of sewage sludge. Int J Environ Res Public Health. 2018; 15: 1717.

29. Szaja A, Montusiewicz A, Lebiocka $M$, Bis $M$. The effect of brewery spent grain application on biogas yields and kinetics in co-digestion with sewage sludge. PeerJ. 2020; 8: e10590.

30. Zahan Z, Othman MZ, Rajendram W. Anaerobic codigestion of municipal wastewater treatment plant sludge with food waste: A case study. BioMed Res Int. 2016; 2016: 8462928.

31. Sahota S, Shah G, Ghosh P, Kapoor R, Sengupta S, Singh P, et al. Review of trends in biogas upgradation technologies and future perspectives. Bioresour Technol Rep. 2018; 1: 79-88.

32. Sivamani S, Saikat B, Prasad BN, Baalawy AA, Al-Mashali SM. A comprehensive review on microbial technology for biogas production. In: Bioenergy research: Revisiting latest development. Singapore: Springer; 2021. pp.53-78.

33. Abanades S, Abbaspour H, Ahmadi A, Das B, Ehyaei MA, Esmaeilion F, et al. A critical review of biogas production and usage with legislations framework across the globe. Int J Environ Sci Technol. 2021. Doi: 10.1007/s13762-021-03301-6.

34. Tian X, Trzcinski A. Effects of physico-chemical post-treatments on the semi-continuous anaerobic digestion of sewage sludge. Environments. 2017; 4: 49.

35. Doloman A, Soboh Y, Walters AJ, Sims RC, Miller CD. Qualitative analysis of microbial dynamics during anaerobic digestion of microalgal biomass in a UASB reactor. Int J Microbiol. 2017; 2017: 5291283.

36. Sarkar S, Banerjee S. Studies on biomethanation of water hyacinth (eichhornia crassipes) using biocatalyst. Int J Energy Environ. 2013; 4: 449-458.

37. Martin Vincent $\mathrm{N}$, Wei $\mathrm{Y}$, Zhang J, Yu D, Tong J. Characterization and dynamic shift of microbial communities during start-up, overloading and steady-state in an anaerobic membrane bioreactor. Int J Environ Res Public Health. 2018; 15: 1399.

38. Sovacool BK. Design principles for renewable energy programs in developing countries. Energy Environ Sci. 2012; 5: 9157-9162.

39. Wang Q, Liang Y, Zhao P, Li QX, Guo S, Chen C. Potential and optimization of two-phase anaerobic digestion of oil refinery waste activated sludge and microbial community study. Sci Rep. 2016; 6: 38245.

40. Masebinu SO. Anaerobic digestion process stabilisation and in-situ upgrading of a biogas system. Johannesburg: University of Johannesburg; 2018.

41. Yeneneh AM, Sen T, Kayaalp A, Ang M. The role of sludge pretreatment on the enhancement of anaerobic digester performance in wastewater treatment plants. In: Physical, chemical and 
biological treatment processes for water and wastewater. Hauppauge: Nova Publishers; 2015. pp.251-282.

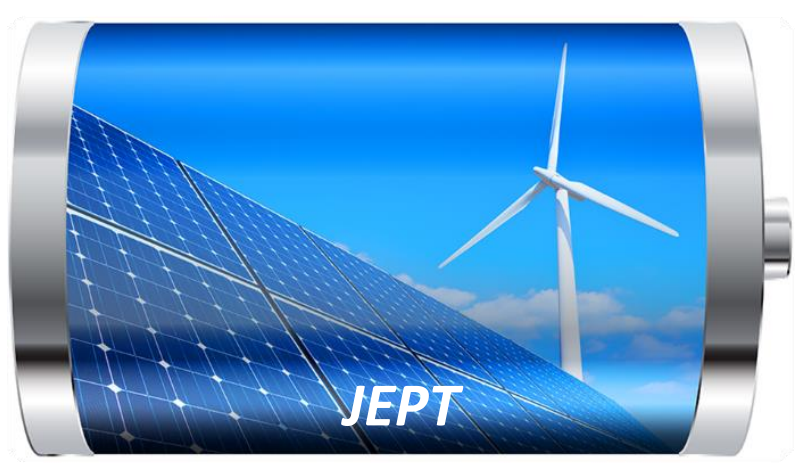

Enjoy JEPT by:

1. Submitting a manuscript

2. Joining in volunteer reviewer bank

3. Joining Editorial Board

4. Guest editing a special issue

For more details, please visit:

http://www.lidsen.com/journal/jept 